\title{
Understanding occupancy pattern and improving building energy efficiency through Wi-Fi based indoor positioning
}

Article

Accepted Version

Creative Commons: Attribution-Noncommercial-No Derivative Works 4.0

Wang, Y. and Shao, L. (2017) Understanding occupancy pattern and improving building energy efficiency through Wi- $\mathrm{Fi}$ based indoor positioning. Building and Environment, 114 (1). pp. 106-117. ISSN 0360-1323 doi:

https://doi.org/10.1016/j.buildenv.2016.12.015 Available at https://centaur.reading.ac.uk/68584/

It is advisable to refer to the publisher's version if you intend to cite from the work. See Guidance on citing.

Published version at: http://dx.doi.org/10.1016/j.buildenv.2016.12.015

To link to this article DOI: http://dx.doi.org/10.1016/j.buildenv.2016.12.015

Publisher: Elsevier

All outputs in CentAUR are protected by Intellectual Property Rights law, including copyright law. Copyright and IPR is retained by the creators or other copyright holders. Terms and conditions for use of this material are defined in the End User Agreement.

www.reading.ac.uk/centaur 
Central Archive at the University of Reading

Reading's research outputs online 


\title{
Understanding occupancy pattern and improving building energy efficiency through Wi-Fi based indoor positioning
}

Y Wang and L Shao

School of the Built Environment, University of Reading, Whiteknights, Reading RG6 6UR, UK.

\begin{abstract}
Detailed visualisation and data analysis of occupancy patterns including spatial distribution and temporal variations are of great importance to delivering energy efficient and productive buildings. An experimental study comprising 24-hour monitoring over 30 full days was conducted in a university library building. Occupancy profiles have been monitored and analysis has been carried out. Central to this monitoring study is the Wi-Fi based indoor positioning system based on the measured Wi-Fi devices' number and locations and data mining methods. Distinct from traditional occupancy and energy studies, more detailed information related to the indoor positions and number of occupants has offered a better understanding of building user behaviour. The implication of the occupancy patterns for energy (e.g. lighting and other building services) efficiency is assessed, assisted with data from lighting sensors where needed. It is found occupancy patterns change dramatically with time. Also, the energy
\end{abstract}


waste patterns have been identified through the method of data association rule mining. If the identified energy waste is removed, the total energy consumption can be reduced by $26.1 \%$. The indoor positioning information also has implications for optimising space use, opening hours as well as staff deployment. The work could be extended to more rooms with diverse functions, other seasons and other types of non-domestic buildings for a more comprehensive understanding of building user behaviour and energy efficiency.

Key words: Building energy efficiency, Occupancy, Wi-Fi based indoor positioning, Data mining, User behaviour.

\section{Introduction}

Energy demand reduction in buildings is a central plank in the effective delivery of low carbon built environment and wider low carbon economy and society. It is increasingly accepted that greater understanding of user behaviours is crucial for substantial and durable energy demand reduction. A large number of previous studies have stressed the importance of occupancy for energy consumption from diverse perspectives, spanning specific technologies to design and operation requirements [1,2]. Occupancy has a great influence on the space heating design and space heating appliances [3]. The latent and sensible heat released from the people inside the building to the surrounding 
indoor environment can make a significant difference to the heating and cooling load [4]. Diversity in occupancy among different space in the same building could pose significant challenges to energy efficiency of heating, ventilation and air-conditioning system (HVAC) $[5,6]$. From the perspective of energy efficiency management, matching the occupancy pattern with provision of building services (e.g., lighting) could allow substantial energy demand reduction. Yun et al [7] discussed the role of occupancy information for maximizing daylighting and minimizing electric lighting. The advent of low-cost wireless sensors as well as advances in information and communication technologies has enabled personal-level energy monitoring and occupancy monitoring in domestic building space usage study [8] and the behaviour study relating to energy consumption of information, communication and entertainment equipment [9]. Studies have also assessed effectiveness of format of personal energy consumption feedback [10] and a series of building energy management research projects (e.g. Wi-be $[11,12])$ have been carried out under the UK RCUK TEDDI programme.

There are a variety of occupancy detection technologies currently available. The deployment of passive infrared (PIR) sensors for occupancy detection is one of the earliest though its effectiveness is often restricted by the fact that these motion sensors cannot normally detect immobile occupants' presence 
[13]. However, research has been carried out by others to overcome this limitation through introducing and optimizing a time delay to PIR sensors data [14] [15] or through adopting probabilistic models [16] [17] to achieve a greater accuracy of presence detection. Nevertheless, limitations of the PIR based approach remain, e.g., its inability to count multiple people walking together. Ultrasound sensors are similar to PIRs in detecting human movements, therefore enjoying similar strengths and suffering from similar limitations [18]. CO2 sensors have been used to assist estimation of occupancy. The low cost and prevalence of the sensors make this approach attractive though care is needed in assessing its reliability which can be affected by varying ventilation rate, door position and outside $\mathrm{CO} 2$ concentration [15]. In order to improve occupancy detection accuracy, methods have been put forward based on a sensor network that integrates diverse measurement types like motion detector, power consumption monitor, $\mathrm{CO} 2$ sensor etc. and combined data mining analysis ([17] [19] [20] [21]). The will allow the information from different sensors to complement each other to reduce the error that would arise from single sensor-type setup. This ongoing research is valuable and will benefit all types of occupancy technologies including that investigated in this study. Ultrawideband (UWB) indoor positioning is highly accurate but the cost is often prohibitively high [22]. Image analysis based on visible and infrared videos have been increasingly used to detect the indoor occupancy with a reasonable 
accuracy, but there is a great concern about the privacy issues. Although the infrared version of the image analysis based method is more privacy friendly, it could not detect occupants behind obstacles like desk screens and bookshelves [23]. Bluetooth positioning technology is accurate and low cost and has lower power consumption but many devices carried around by building users do not enable Bluetooth transmission making this technology often ineffective for indoor location determination [24]. An emerging technology is the Wi-Fi based indoor positioning, which is capable of determining the real-time numbers and locations of occupants. Its configuration is relatively simple and system components relatively low-cost. Furthermore, Wi-Fi is widely activated in mobile devices and the Wi-Fi based occupancy detection is relatively privacy friendly (especially after enhance measured as described in Section 2). As a result, the Wi-Fi based indoor positioning technology is selected for the presented investigation.

The presented work focuses on a university library, given that the further and higher education (FE and HE) sector consumes a significant amount of energy and annually the energy cost of buildings in the FE and HE in the UK is approximately $£ 400$ million with annual $\mathrm{CO} 2$ emissions of 3 million tons [25]. A 30-day continuous experiment has been conducted in the Knowledge Exchange Room in the library of University of Reading, UK, to gather the 
occupancy information by using the advanced Wi-Fi based Navizon indoor triangulation system. The occupancy information could be used to facilitate building energy reduction in a broad range of domains including electric appliances, HVAC and lighting systems. In this work, lighting energy waste analysis is conducted to illustrate this approach.

\section{Experiment method}

This 30-day continuous experiment including 15 days in the summer term and 15 days in the summer vacation has been done in the Knowledge Exchange Room, with an area of about $126 \mathrm{~m}^{2}$, on the ground floor of library in the University of Reading, UK. The whole library is covered by a secure and stable 2.4 GHz Wi-Fi network that is only accessible for registered campus students and staff. 




Figure 1. The library in University of Reading

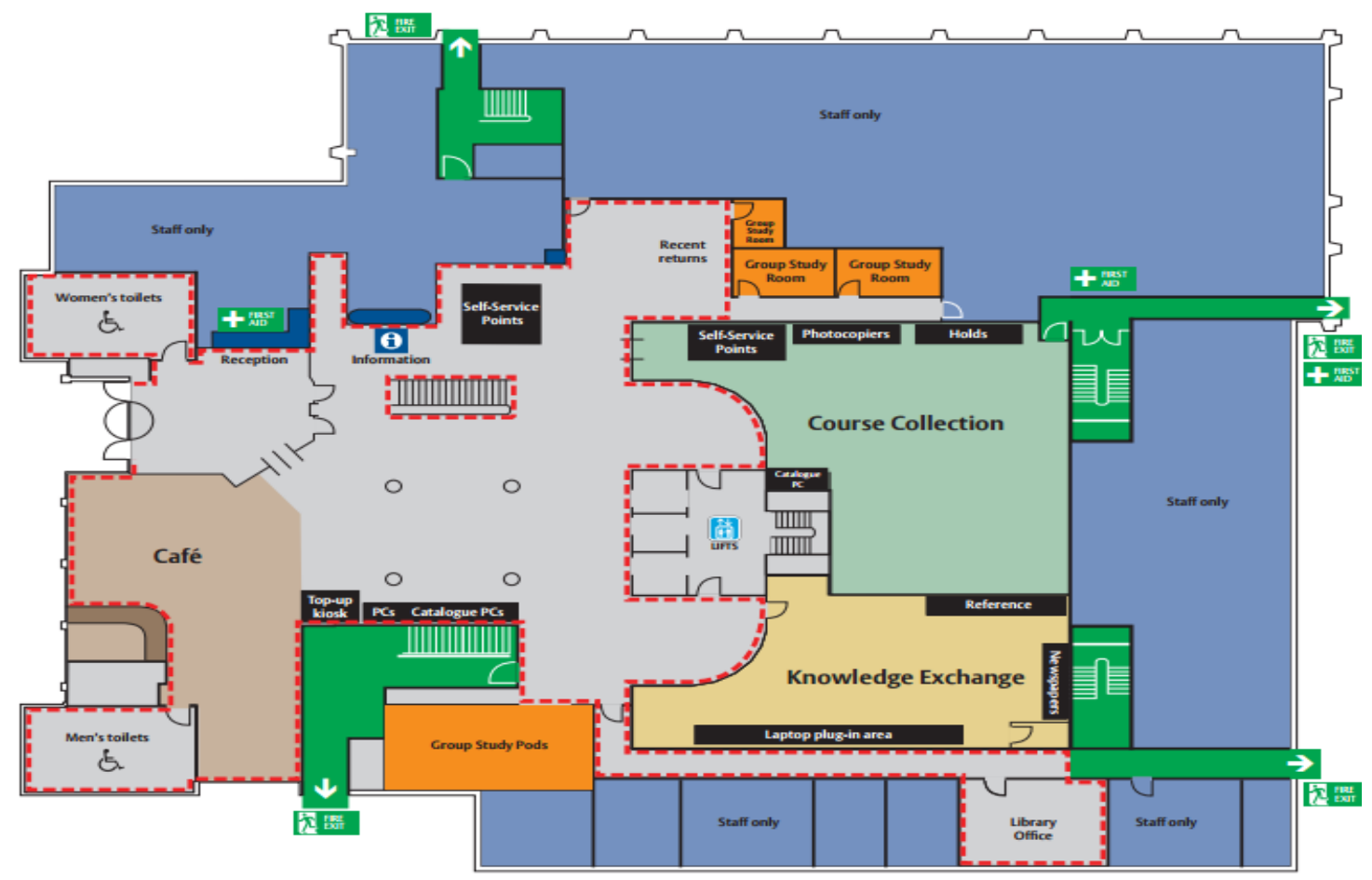

Figure 2. Floorplan of library ground floor 


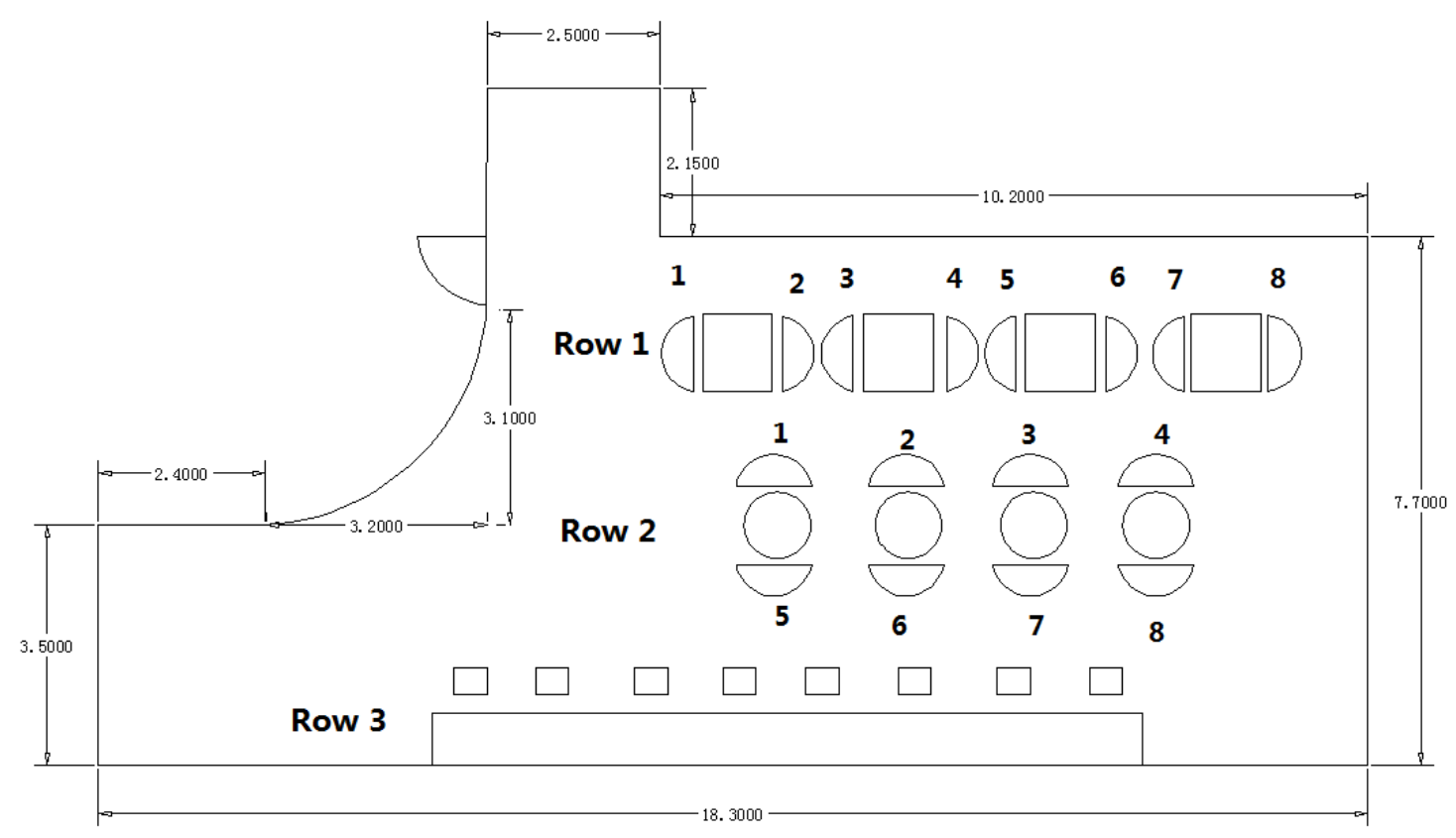

Figure 3. Dimension of the Knowledge Exchange Room

Table 1. Library opening schedule during the test period

Time period

Opening schedule

\begin{tabular}{cl}
\hline Summer tem (27 $7^{\text {th }}$ May-10th June) & $\begin{array}{l}24 \text { hours/ } 7 \text { days opening except } \\
\text { from } 21 \mathrm{pm} \text { on Saturday to } 8.30 \mathrm{am} \\
\text { on Sunday }\end{array}$ \\
Summer vacation (11th- 26th June) & $\begin{array}{l}\text { Open from } 8.30 \text { am to } 5 \mathrm{pm} \text { on } \\
\text { weekdays and closed on weekends }\end{array}$ \\
\hline
\end{tabular}



Figure 4. A measurement node of ITS system 
The Navizon Indoor Triangulation System (ITS) is deployed for real-time location detection of Wi-Fi enabled devices. It calculates the coordinates of devices by measuring the length, the angle, the side of one triangle of the device point and two existing known reference signal points. The whole system consists of the Accuware server and measurement nodes (shown in Figure 4). The nodes act as the Wi-Fi access points (AP) for detecting $2.4 \mathrm{GHz}$ Wi-Fi signals and sending data to the Accuware server for location estimation of detected Wi-Fi devices. To ensure accuracy, it is required that spacing between nodes is within $12 \mathrm{~m}$ [26]. In this research, authors typically use node separations of about 5-10 m. A total of 6 measurement nodes were deployed in this experiment, as shown in Figure 5. The combined cost of the sensors came to $£ 500$. Obviously the cost would be reduced if a less dense sensor network is deployed. At least one node needs to be connected to the Internet and it is referred as the gateway, while others are used as repeaters. Detectable devices include smartphones, tablets and laptops in any Wi-Fi network. The scan rate of nodes is set at once 5 seconds constantly, but not every Wi-Fi enabled device can be detected at this frequency, since some devices may generate $\mathrm{Wi}-\mathrm{Fi}$ traffic at other constant frequency and some devices may transmit signals more irregularly [26]. 


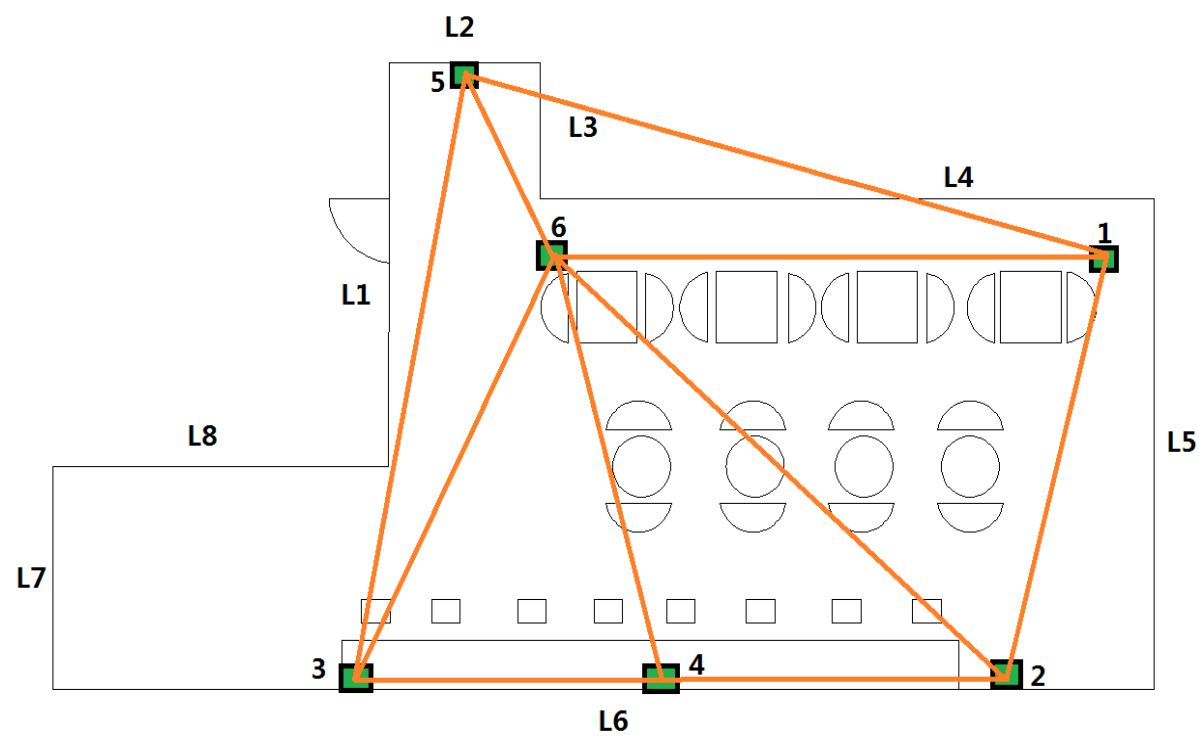

Figure 5. Nodes placement plan

The collected data were sent from nodes to the Navizon server through a $3 G$ mobile Wi-Fi router (Huawei Mobile Connect E169G). Only the Mac address and corresponding location (latitude and longitude) with UNIX time stamp were collected, so no direct personal identification information was gathered in the study. All the acquired information is presented in the daily CSV file which can be assessed only by the authorized person from the official website using account ID and password for privacy and security protection. What is more, just the last 6 numbers or characters of the Mac address in the original data were kept for analysis and the other parts were removed so that it is extremely difficult to identify the full device MAC number. This approach was proved to have no effect on the database and data analysis accuracy, as the remaining character string after blocking off its half digits is still practically unique for the purpose of occupancy pattern study. Also, this room floorplan is simplified with 8 lines (L1- 
L8) as shown in Figure 5, with $1.7 \%$ area reduction, so it is supposed to have no effect on the result.

This room is in the inner part of the building with no windows, which is beneficial to lighting measurement. All lights are collectively switched. A HOBO U12-012 Temp/RH/Light/Ext Data Logger was placed at the height of $2.0 \mathrm{~m}$ against a wall so that the illuminance from the lights cannot be easily blocked by people during the experiment. It needs to be stated that the lighting sensor is only used to check if light is on so strict accuracy is not necessary and placement is not critical.

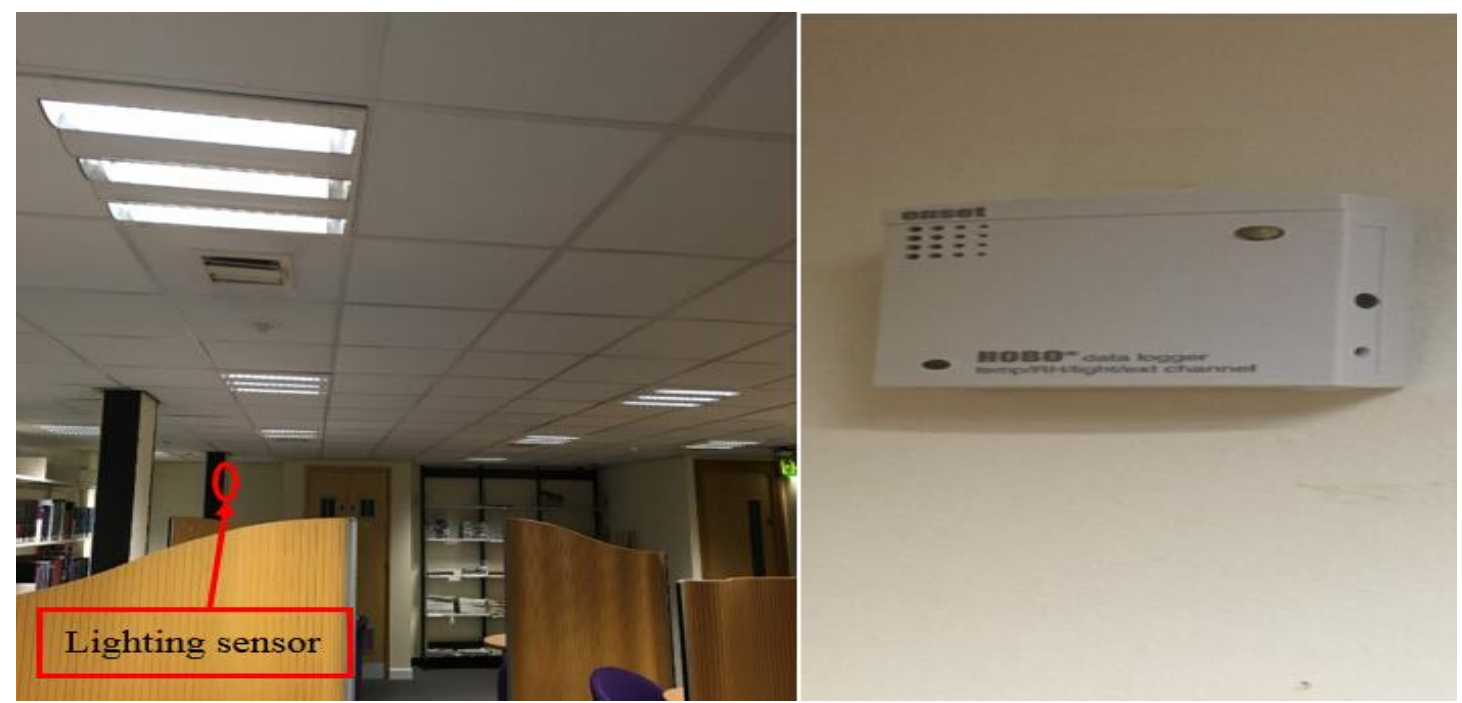

Figure 6. The lighting sensor

\section{Calculation}

Raw data downloaded from the Navizon server contains MAC addresses of detected Wi-Fi devices, their longitudinal and latitudinal coordinates as well as the times of detection, presented through Unix time stamps. Raw data is 
grouped by the Mac addresses, and three kinds of software are involved in data analysis: Matlab, Visual Basic and the open source software R. Specifically, Matlab is used for the location determination, and Visual Basic is for occupancy time determination, and $\mathrm{R}$ is for further data mining.

A particular question to answer in data analysis is whether the device is within the room being investigated. In this case, the room walls are parallel to neither the longitude nor the latitude coordinate lines, so simple comparisons of longitude and latitude values could not reveal whether a device is within the room. The function of ' $I N=$ inpolygon $(X, Y, X V, y v)$ ' in Matlab is deployed to carry out this location determination. This function is usually used to decide whether a known coordinate is inside the given area. Basically, after the matrix of locations of devices ( $\mathrm{Y}=$ latitude and $\mathrm{X}=$ longitude) is put into the Matlab, IN = inpolygon $(X, Y, X V, y v)$ will return a matrix, called 'IN', in the working sheet of Matlab or other specified file, in the same size of $X$ and $Y$. If $I N=0$, it means $(X$, $Y)$ is outside the polygonal region, while if $I N=1$, it means $(X, Y)$ is inside the region.

Detection rate of a given $\mathrm{Wi}-\mathrm{Fi}$ device is dependent on the $\mathrm{Wi}-\mathrm{Fi}$ traffic generated by the device, which in turn is dependent on the make and model of the device and its operation mode. For example, a device in sleep mode will 
generate less-frequent $\mathrm{Wi}-\mathrm{Fi}$ traffic thus the rate of detection of the device will be lower, i.e. there will be a longer period between two successive detections of the device. Previous studies by the manufacturer and at the University of Reading have shown that over $97 \%$ of Wi-Fi enabled devices in 'sleep mode' could be detected by the measurement nodes within 90 seconds [26]. So it is reasonable to make the assumption that if the time interval between $t$ (i) and $t$ (i+1) of the same Mac address in the raw data file is more than 90 seconds, this device is supposed to be not in the detection area during the period between $t$ (i) and $t(i+1)$.

It is often required to count the device number in the room at a given time or for a test period. A Visual basic program is produced to do the counting [27]. Further investigation into patterns of occupancy and implications for energy efficiency was conducted using data mining techniques. There is a great variety of techniques in the field of data mining including predictive model, decision tree model, cluster analysis, and mining through association rules. For this work, data association rule technique is applied. Each association rule comprises the antecedent and the consequent, or the left hand side $(A)$ and the right hand side (B), respectively. An association rule usually has a structure of ' $A \Rightarrow B$ '. The conspicuousness and correctness of each association rule is measured by confidence, support and lift [27, 28]. 


$$
\begin{aligned}
& \text { Support }(\mathrm{A} \Rightarrow \mathrm{B})=\mathrm{P}(\mathrm{A} \cap \mathrm{B}) \\
& \text { Confidence }(\mathrm{A} \Rightarrow \mathrm{B})=\mathrm{P}(\mathrm{B} \mid \mathrm{A}) \\
& \operatorname{Lift}(\mathrm{A} \Rightarrow \mathrm{B})=\frac{\operatorname{support}(A \cup \mathrm{B})}{\operatorname{support}(A) \times \operatorname{support}(B)}
\end{aligned}
$$

Various algorithms exist to test the association rules when applied to a data set. These differ in terms of computing resources required [29]. Given that Gigabytes of data could be generated from this test site and associated processing time could be nearly 1 hour on a moderate laptop computer, it is still necessary to choose proper association algorithms to reduce the computing work. In this work, the Apriori algorithm is adopted to assess the association rules for use. It is one of the most classical and effective algorithms commonly used to identify the frequent occurring items from a large data set [30]. Symbols representing different attributes involved the data association rule mining are defined in the Table 2. In addition, lighting energy waste is defined as the lighting is on, while there are no occupants; otherwise, it is non-energy waste. 
Table 2. Definition of symbols

\begin{tabular}{|c|c|}
\hline Symbols & Definition \\
\hline $\mathrm{Y}$ & $\begin{array}{l}\text { Yes, there exits energy waste (lights on while not } \\
\text { occupied) }\end{array}$ \\
\hline $\mathrm{N}$ & No, there is no energy waste (occupied) \\
\hline A1 & $1 \mathrm{am}$ to $9 a m$ in a day \\
\hline $\mathrm{A} 2$ & 9am to $5 p m$ in a day \\
\hline A3 & $5 p m$ to 1 am (the next day) \\
\hline B1 & Weekdays \\
\hline B2 & Weekends \\
\hline C1 & During the summer term ( $27^{\text {th }}$ in May to $10^{\text {th }}$ in June) \\
\hline $\mathrm{C} 2$ & During the summer vacation ( $11^{\text {th }}$ to $26^{\text {th }}$ in June) \\
\hline
\end{tabular}

In addition, a further series of sampling tests in 14 separate days with 1-hour period has been carried out during the investigation period to determine the correlation between occupant number (ON) and the Wi-Fi device number (DN). The ON is from direct manually counting by the author acting as an occupant thus not disturbing others, while the DN is obtained using the occupancy detection system and algorithms mentioned above. The sampling date and time period are detailed in Table 3. In each of the 14 sampling sessions, the author sampled multiple times and calculated the DN/ON for each sample. The average of DN/ON Ratio for all sampling data is calculated according to equation (4). This ratio is used to indicate any disparity between DN and ON, in other words, the accuracy of Wi-Fi based system for occupancy counting. It should be noted that it does not mean that the ratio needs to be approaching 1 for the system to be useable. As long as one is aware of the DN/ON disparity 
level, the occupancy patterns revealed by the system would still be meaningful.

$$
\left(\frac{D N}{O N}\right)=\sum_{1}^{n} \frac{(D N)_{i}}{(O N)_{i}}
$$

Where $\left(\frac{D N}{O N}\right)$ is the average DN/ON ratio; $(D N)_{i}$ is the number of device in the i th sample; $(O N){ }_{i}$ refers to the number of occupants in the $\mathrm{i}$ th sample; $\mathrm{n}$ refers to the total number of samples in the test; $\mathrm{i}$ is the sample number ranging from 1 to $n$.

Table 3. Sampling test arrangement

\begin{tabular}{ccc}
\hline Sampling test & Date & Time \\
\hline 1 & $27^{\text {th }}$ May & $10 \mathrm{am}-11 \mathrm{am}$ \\
2 & $28^{\text {th }}$ May & $3 \mathrm{pm}-4 \mathrm{pm}$ \\
3 & $29^{\text {th }}$ May & $7 \mathrm{pm}-8 \mathrm{pm}$ \\
4 & $1^{\text {st }}$ June & $8 \mathrm{pm}-9 \mathrm{pm}$ \\
5 & $2^{\text {nd }}$ June & $8 \mathrm{am}-9 \mathrm{am}$ \\
6 & $4^{\text {th }}$ June & $1 \mathrm{pm}-2 \mathrm{pm}$ \\
7 & $7^{\text {th }}$ June & $1 \mathrm{am}-2 \mathrm{am}$ \\
8 & $8^{\text {th }}$ June & $6 \mathrm{am}-7 \mathrm{am}$ \\
9 & $10^{\text {th }}$ June & $10 \mathrm{pm}-11 \mathrm{pm}$ \\
10 & $13^{\text {th }}$ June & $10 \mathrm{am}-11 \mathrm{am}$ \\
11 & $15^{\text {th }}$ June & $12 \mathrm{pm}-1 \mathrm{pm}$ \\
12 & $16^{\text {th }}$ June & $3 \mathrm{pm}-4 \mathrm{pm}$ \\
13 & $21^{\text {st }}$ June & $2 \mathrm{pm}-3 \mathrm{pm}$ \\
14 & $22^{\text {nd }}$ June & $9 \mathrm{am}-10 \mathrm{am}$ \\
\hline
\end{tabular}

\section{Results and discussions}

A series of 5 tests have also been carried out to verify the location accuracies of the ITS system. Two Wi-Fi devices with the Mac addresses XXXXXX3FBC3B 
and XXXXXX1D0BA0 respectively were used in these tests. The outcomes of the 5 tests are summarised in Figure 7. The green dots are the locations of the measurement nodes and the yellow dots are the positions of Wi-Fi devices used in these tests. The ITS location system accuracy was consistently around 0.5meter in these tests. Besides, the frequencies of occurrences (in \%) of the individual DN/ON ratios found are presented in Figure 8 . It is clear that the $\mathrm{DN} / \mathrm{ON}$ ratio of 1 is dominant in terms of occurrence frequency. The average of $\mathrm{DN} / \mathrm{ON}$ ratio for all sampling data is calculated as 1.16 . This level of disparity is in authors' opinion acceptable in the context of this study and one will be able to extract meaningful occupancy patterns in the library from the collected data.

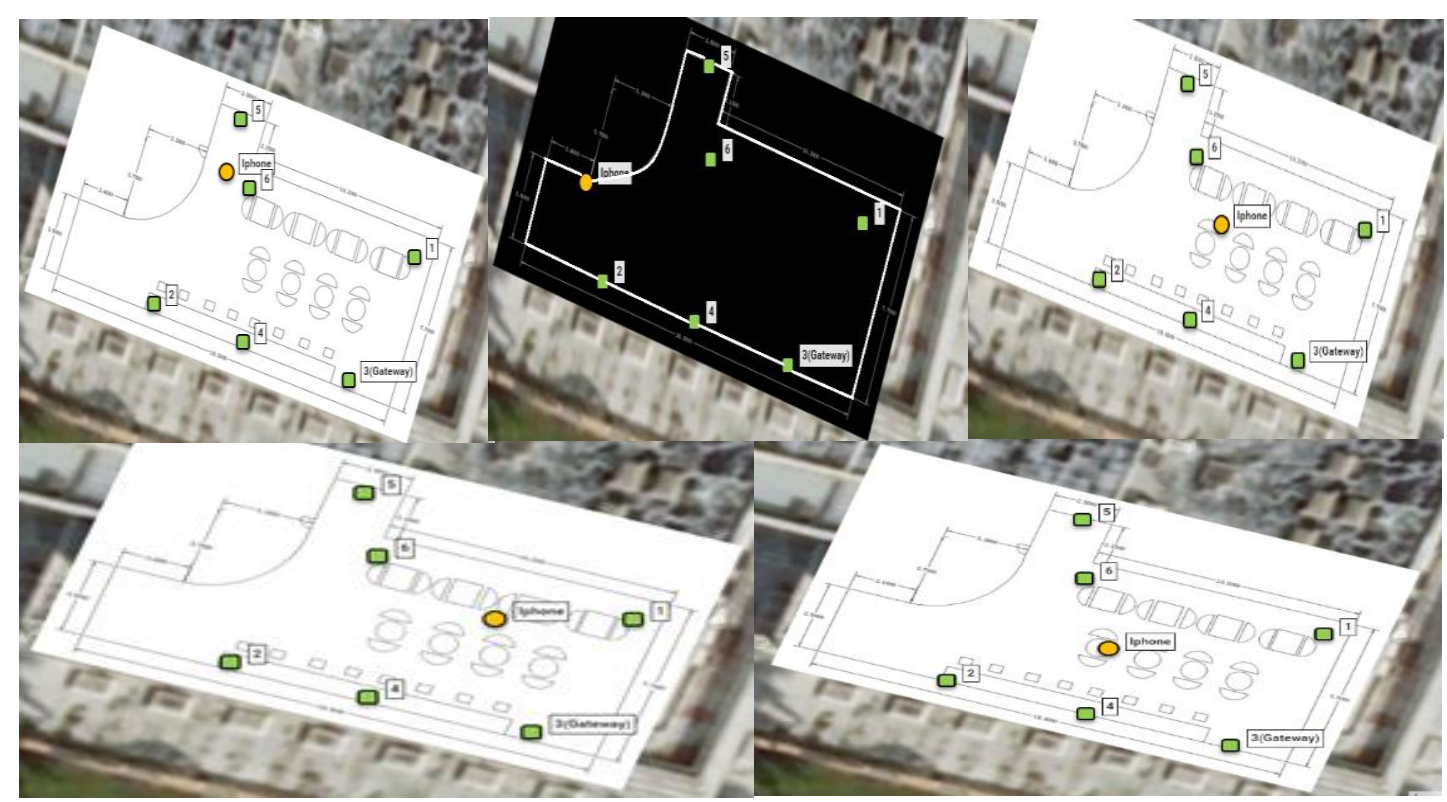

Figure 7. Test 1-5 (from the top left to bottom right) 


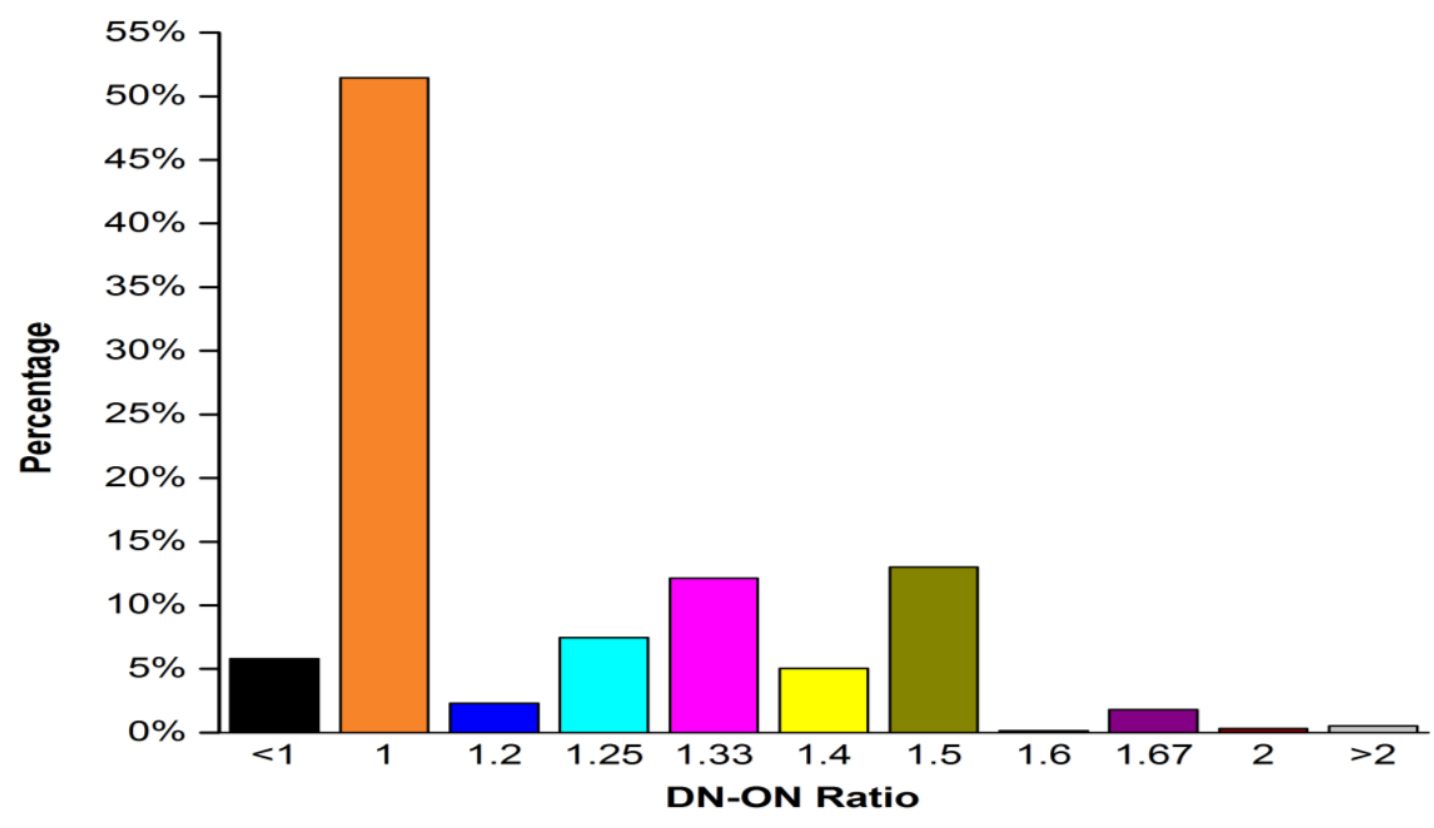

Figure 8 . The frequency of individual $D N / O N$ ratio

It is worth pointing out that throughout the 30-day test period, the ITS system has exhibited excellent reliability and data quality. One brief episode of data loss was encountered due to the Internet network disconnection $(0.012 \%$ data loss). Otherwise there was no other problem in data gathering, collection or other general quality issues. The average time interval (frequency) of detection of Wi-Fi devices is $35 \mathrm{~s}$ given a good density of data suitable for occupancy study in academic buildings.

Figure 9 and 10 show detected 'footprints' of Wi-Fi devices in and around the room under investigation. 'Footprints' is used here to describe the space distribution of detected $\mathrm{Wi}-\mathrm{Fi}$ enabled devices within a given time period. In these two Figures, the red spots represent the locations of devices inside the 
room and the blue ones for those outside. Results from one typical day (6th June) in the summer term are presented in Figure 9 and one typical day (15th June) in the summer vacation in Figure 10.

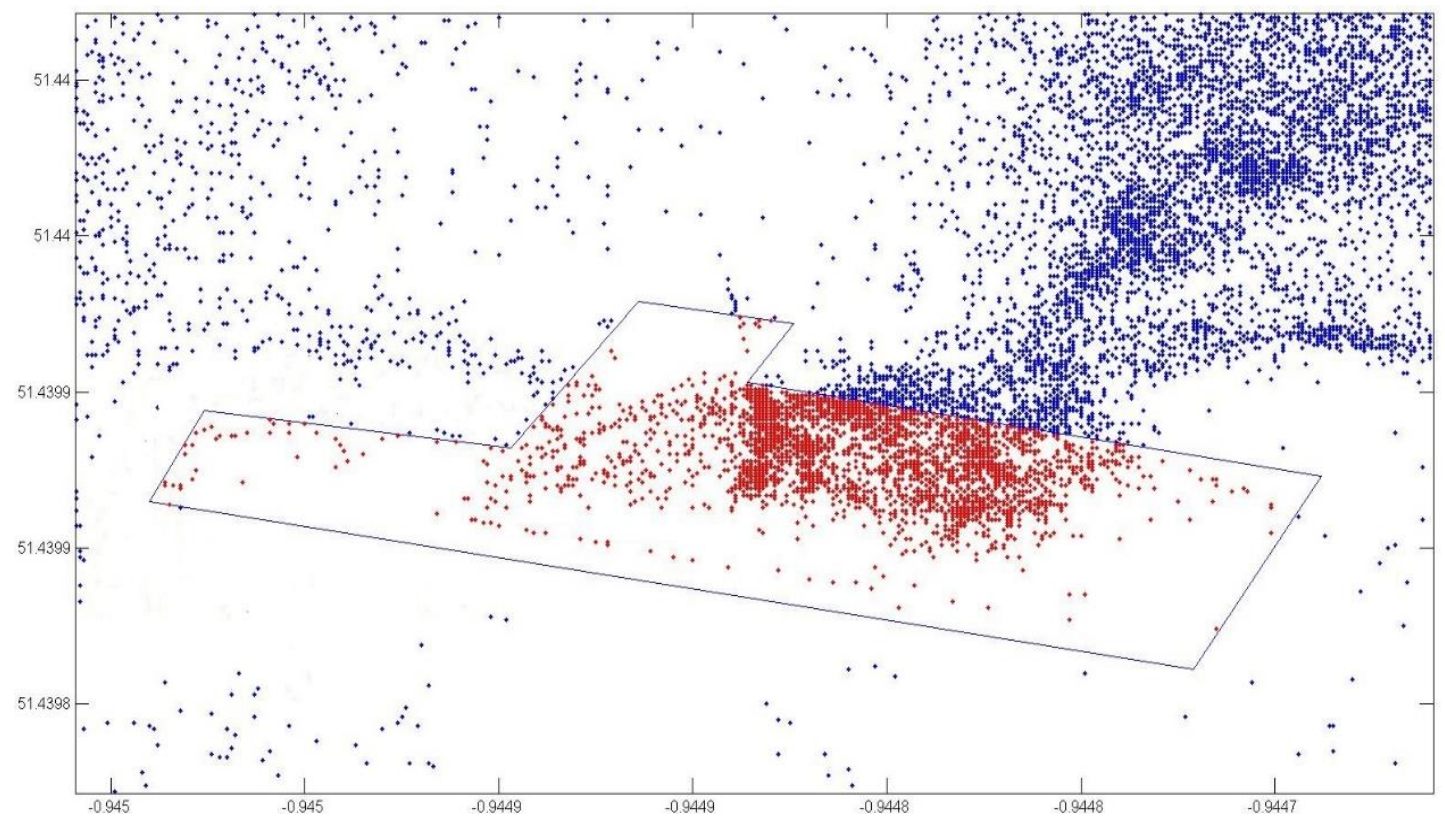

Figure 9. Detected devices footprints on $6^{\text {th }}$ June

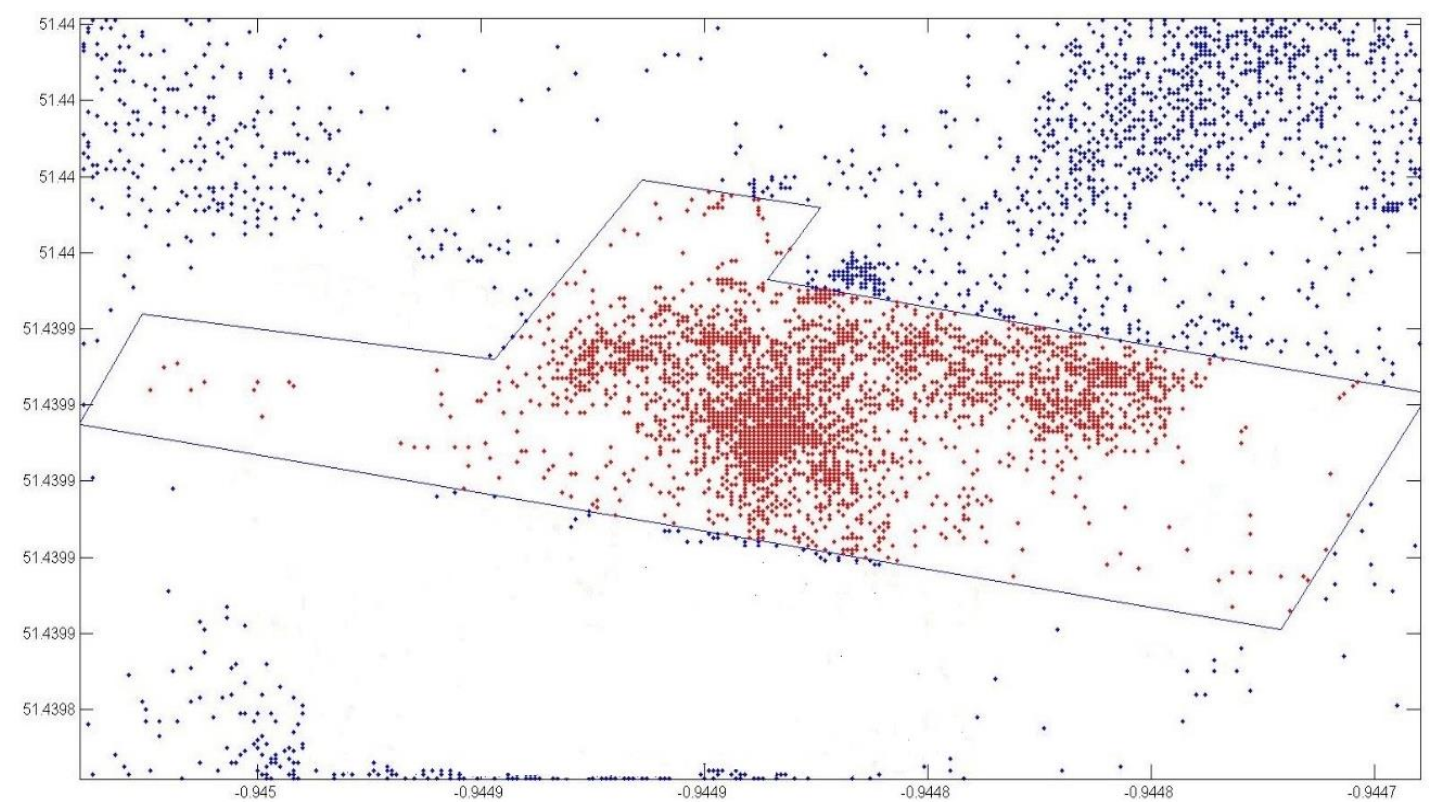

Figure 10. Detected devices footprints on $15^{\text {th }}$ June

There is obvious concentration of footprints near the door area in the Line 1 
(marked in Figure 5) and nearby circulation area in both Figures. This is in line with expectations as this is the main route used by people coming into or out of this room. And significant concentration of Wi-Fi devices can be also seen along the Line 4 (marked in Figure 5), where lies a book shelf with two sides, so it is not surprising to see a lot of footprints detected on both sides of Line 4 . There are also some marked differences between these two days. On $6^{\text {th }}$ June, more devices were found inside the room and these devices were concentrated around the tables with multiple chairs. This is in line with the student behaviour during this part of term time, i.e. focusing study for examinations and coursework submissions. On $15^{\text {th }}$, more devices were shown outside the room and devices inside room had a scattering spatial distribution, away from the tables. These more qualitative observations are highly valuable for direct visual assessment of the type and effective use of the library space and the visualisation of footprints is facilitated by pictures produced through the Matlab. The pattern of footprints distribution becomes even more informative when viewed together with quantitative information, discussed below. 


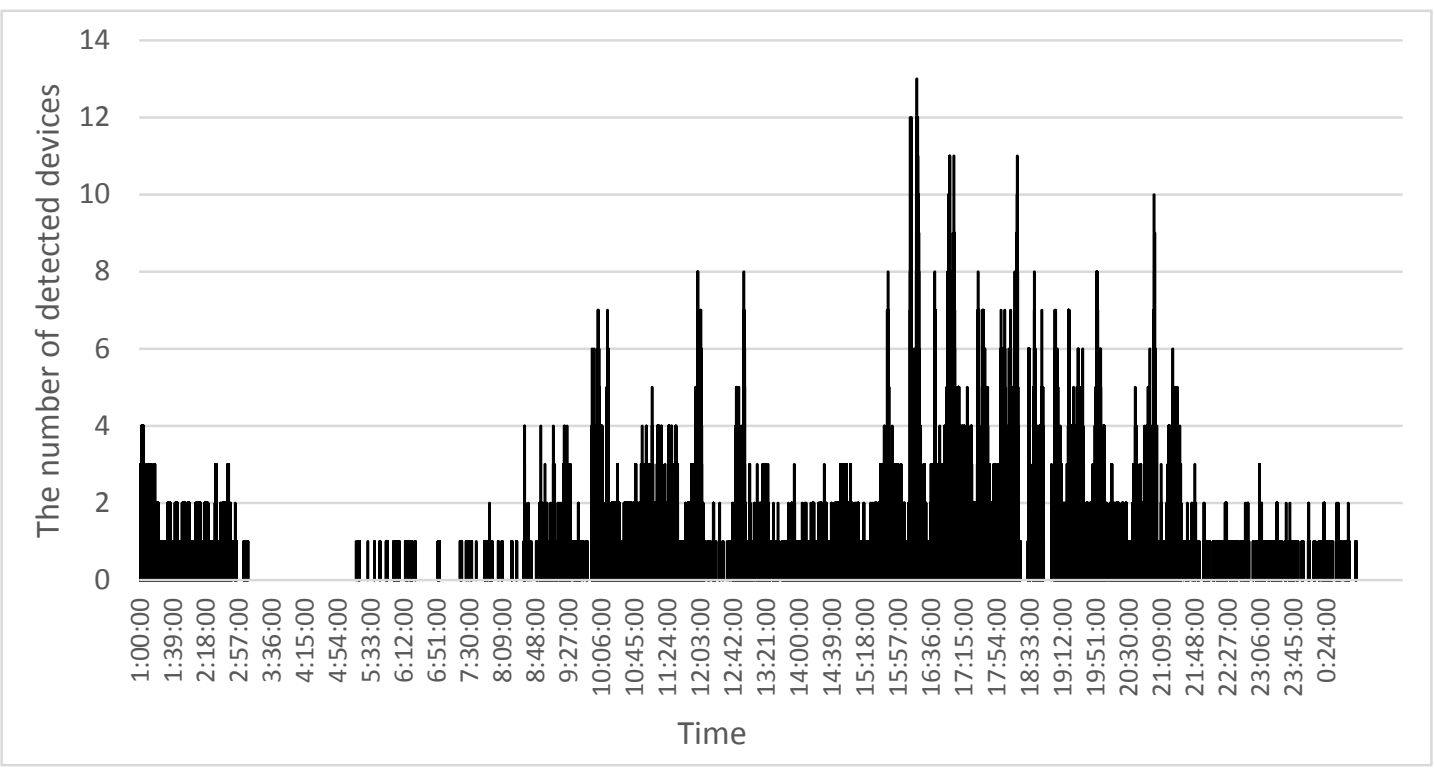

Figure 11. The number of detected Wi-Fi devices on $6^{\text {th }}$ June

Figure 11 shows the number of devices detected throughout a 24 -hour period on 6th June. One main feature is this room was almost continuously occupied on this day except for 2 hours in early morning. Actually there is a mini-peak of occupancy in the midnight just after 1 am. Similar patterns were found in other days during the summer term. This first look at the occupancy pattern justifies the University decision to open the library 24 hours a day during term times. However, detailed examination shows significant room for improvement. Figure 11 also shows two peak periods of use during the day. A moderate peak is from about 9 am to 12 am, while the main peak is from around $3 \mathrm{pm}$ to $10 \mathrm{pm}$, with maximum of 13 devices. In the rest of time, only 1-2 devices were found in this room. This indicates that some people came into the room in the late morning, and after a few hours study, they left for lunch. More people came from the midafternoon to late evening. This pattern including the most popular period 
between 3 pm-10 pm is in line with anecdotal evidence the research team came across but the Wi-Fi based occupancy data generated the hard evidence and much more detailed information. The implication of this information for energy efficiency and space use rationalisation is significant. Although the library operates a 24-hour opening policy during term time, for over $90 \%$ of the period between 1 am and 9 am, the occupancy is limited to 1 or 2 people. Similar patterns can be found in other summer term days. This room could well be closed and users in this room and scattered sparsely in other study rooms could be directed to a common, appropriate space resulting in significant reduction energy use in lighting and other building services. If such space use rationalisation is extended further, with starting timing moving back to $10 \mathrm{pm}$, there would be a significant energy saving potential (up to $42 \%$ reduction for lighting alone for the targeted room).

Figure 12 shows the number of detected Wi-Fi devices during a day, $15^{\text {th }}$ June, in Summer Vacation, when the University operates an 8.5-hour (8.30 am-5 pm) opening policy for the main library. It is obvious that the number of devices is distributed more uniformly with an average of 4-8 devices, compared to that in Figure 11. The good levels of library use reflect the fact that the University is research intensive and has a large population of postgraduate students and contract researchers as well as academic staff who are engaged in research 
during holiday periods for undergraduate students. Noticeably, device number began to grow significantly in the late morning, which may indicate most student still could not go to the library very early. Importantly, the main peak started at $3 \mathrm{pm}$, as in term time, but curtailed at $5 \mathrm{pm}$ when the library closed. There were still a large number of devices (or occupants) in the room even a few minutes before the library was closed. This occupancy pattern is suggesting that these occupants still wanted to continue study but had to leave because of library closure. Similar patterns can be found in other summer vacation days. So from the perspective of library users during the summer vacation period, it is recommended to extend the opening time or shift some of the morning opening hours to early evening, which may lead to more productive study and research for a large group of the university members.

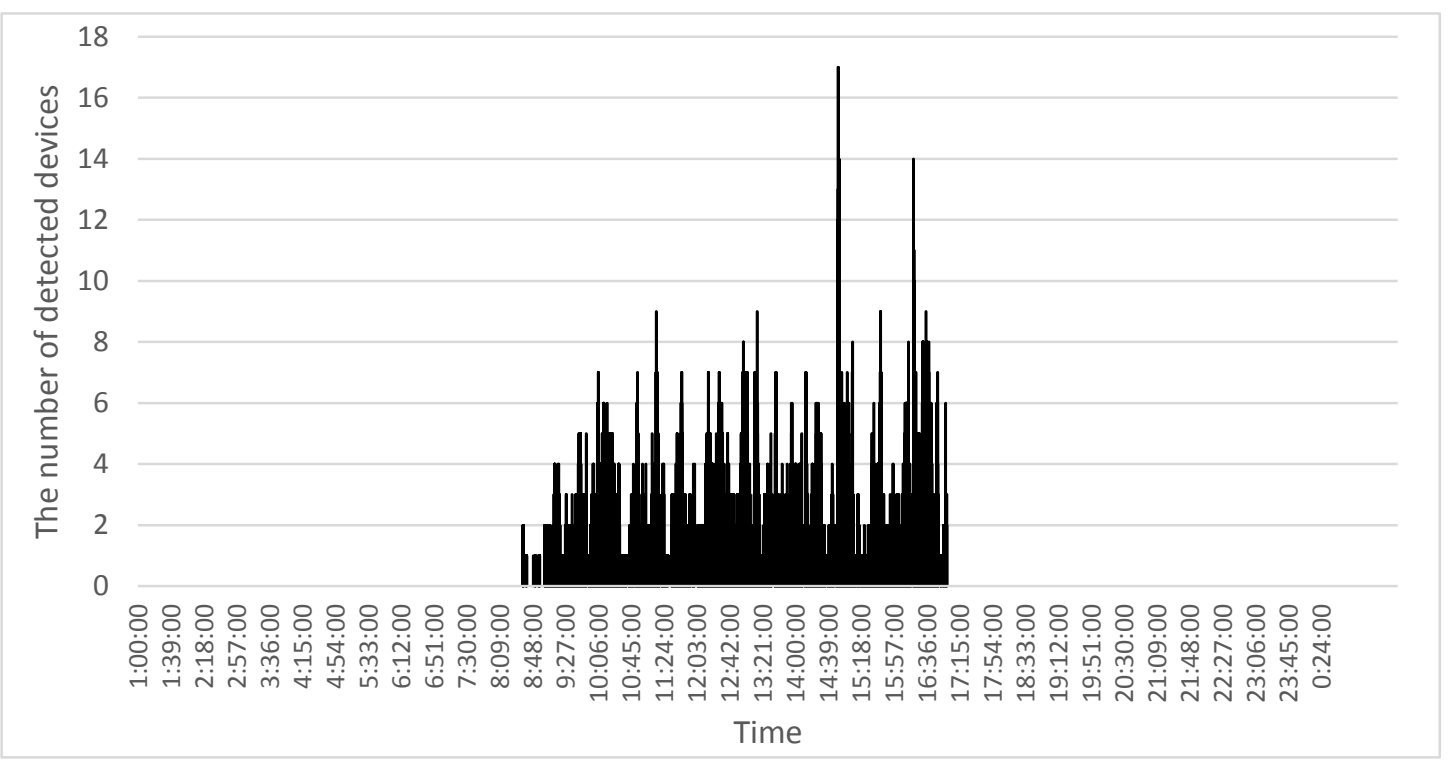

Figure 12. The number of detected Wi-Fi devices on $15^{\text {th }}$ June

Figures $13-15$ present the results on the extent of lighting energy waste in the 
room under investigation. This paper focuses on occupancy detection and analysis with some simple analysis of the implication of such information for energy efficiency. It should be stated in advance that all lights in the room under investigation were working at full power capacity all the time when the library was open and the lights were switched on and off centrally and simultaneously. The Figures below presenting percentage values of lighting energy waste are based on the assumption that when the room is not occupied, the lighting energy consumed in that room is wasted. Although this assumption is simplistic, it does provide a useful indication of the energy saving opportunities identified through detailed occupancy studies. It should be pointed out that energy savings are not limited to lighting. Heating, cooling, ventilation, computer and equipment could all be switched off or reduced, resulting in further energy savings.

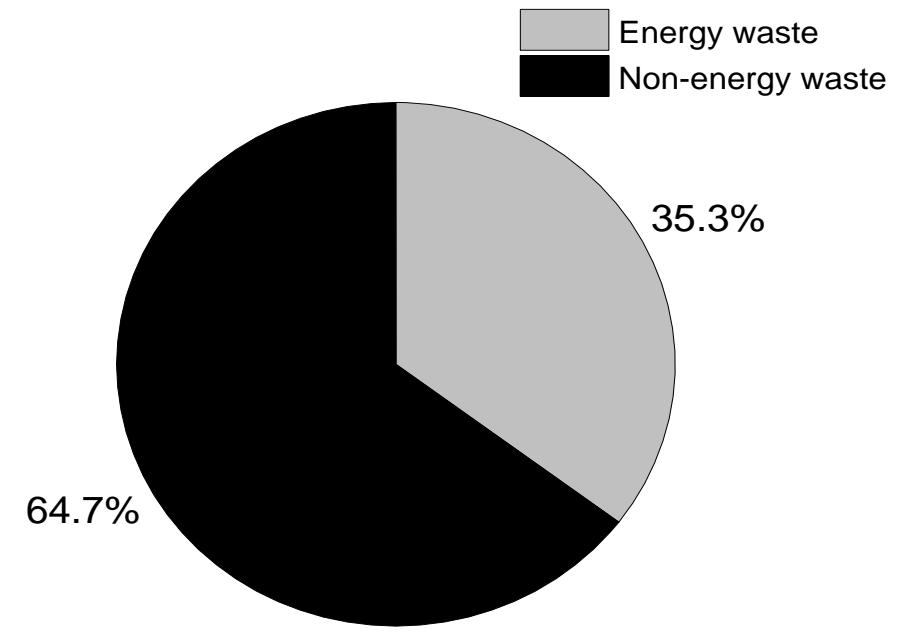

Figure 13. The percentage of total energy waste 


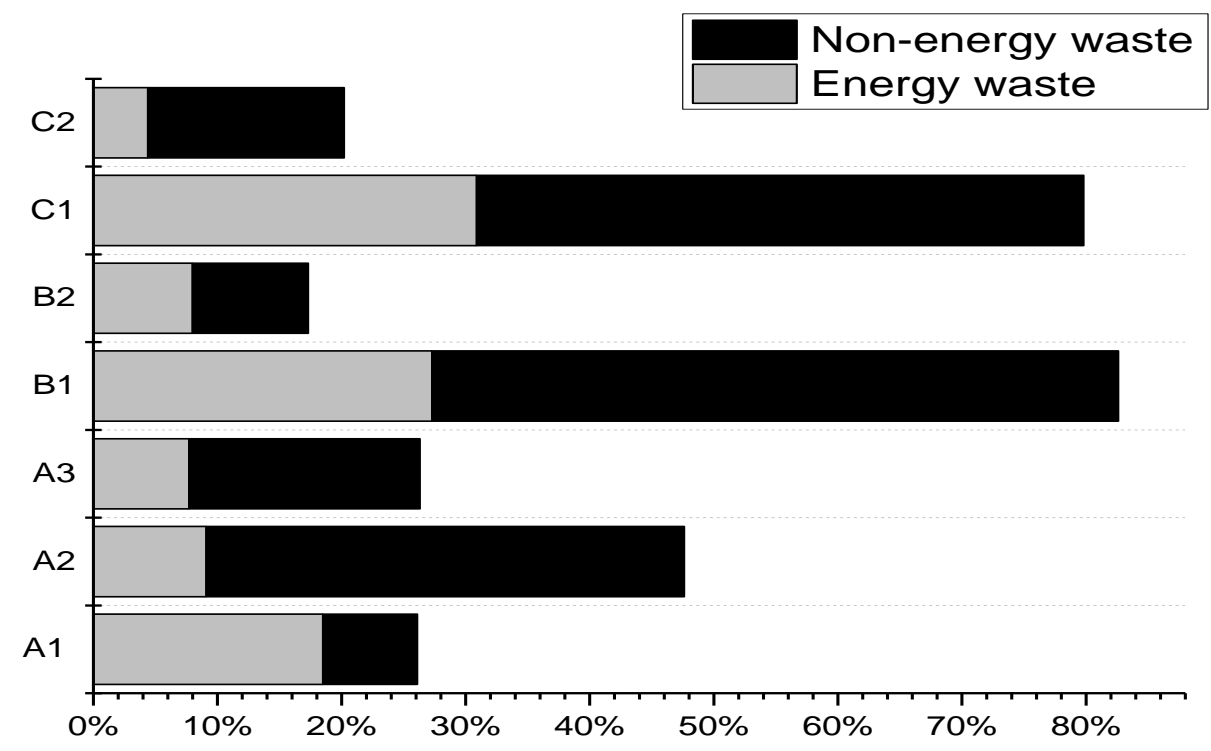

Figure 14. The distribution of energy waste in each time period

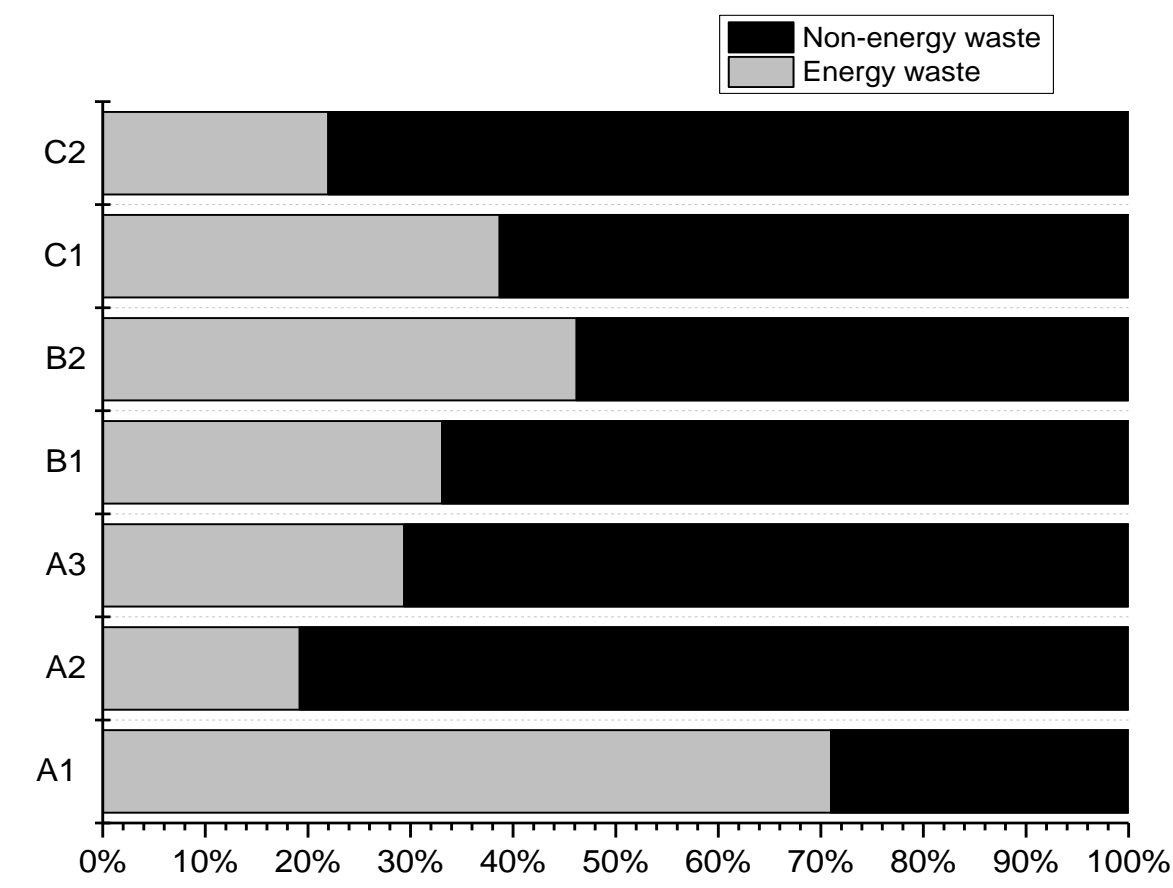

Figure 15. The percentage of energy waste within each time period

During the 30-day monitoring period, the overall lighting energy waste was $35.3 \%$. This also means energy waste occurred in $35.3 \%$ of total monitoring time. It needs to be explained that in Figure 14, the percentage is the ratio of energy waste for each attribute (i.e., weekday + weekend; term time + vacation 
time; time periods of a day) as a whole, while in the in Figure 15, the percentage value is for each part of any given attribute. Note although 15 days of monitoring were included in both term (C1) and vacation (C2) periods, the amount of time for $\mathrm{C} 1$ and $\mathrm{C} 2$ is not the same due to different opening hours of the library during these two periods.

Assessing occupancy pattern and associated implications for (lighting) energy efficiency for a single day can be done by hand using time series charts, but to carry out this for large number of days and establish if a pattern persists across the test period, it is necessary to conduct the data analysis through data mining techniques such as association rules outlined in Section 3. Over 100 association rules were operated on the data sets and useful outcomes are presented in Table 4. It is shown for example lighting energy waste is $65.5 \%$ during the period 1 am to 9 am on weekdays in the summer term (the corresponding value for weekends is much higher). More importantly, it is shown that the time period of 1 - 9 am was responsible for far more lighting energy waste $(71 \%)$ than any other 8 -hour period during the whole experiment time, although there was significant variation between weekdays and weekends. If this room was closed during this period, the total energy waste would be reduced by $26.1 \%$. 
Table 4. Interpretation of extracted rules in the second selection

\begin{tabular}{l}
\hline Rule $\quad$ Indication \\
\hline 1
\end{tabular} $\begin{aligned} & \text { (1) Lighting energy waste exists in } 71.0 \% \text { of time from } 1 \mathrm{am} \text { to } 9 \mathrm{am} \\
& \text { in all days; } \\
& \text { (2) Energy waste happening in this time period takes up } 18.5 \% \text { of } \\
& \text { the whole experiment period. } \\
& \text { (1) Lighting energy waste exists in } 70.6 \% \text { of time from } 1 \mathrm{am} \text { to } 9 \mathrm{am} \\
& \text { in the summer term; } \\
& \text { (2) Energy waste happening in this period takes up } 17.6 \% \text { of the } \\
& \text { whole experiment period. } \\
& \text { (1) Lighting energy waste exists in } 66.2 \% \text { of time from } 1 \mathrm{am} \text { to } 9 \mathrm{am} \\
& \text { on weekdays; } \\
& \text { (2) Energy waste happening in this period takes up } 14.5 \% \text { of the } \\
& \text { whole experiment period. } \\
& \text { (1) Lighting energy waste exists in } 65.5 \% \text { of time from } 1 \mathrm{am} \text { to } 9 \mathrm{am} \\
& \text { on weekdays in the summer term; } \\
& \text { (2) Energy waste happening in this period takes up } 13.7 \% \text { of the } \\
& \text { whole experiment period. }\end{aligned}$

\section{Conclusion}

Real-time and accumulative/historical data on detected Wi-Fi devices has allowed the detailed visualisation and analysis of occupancy patterns including spatial distribution and temporal variations. This information has been shown to have major implications for energy efficiency, space use rationalisation, and productivity. Distinct from traditional occupancy and lighting energy studies, more detailed information related to the indoor positions and number of occupants has offered a better understanding of building user behaviour. Through comparison and analysis of occupancy profiles, it is found occupancy patterns change dramatically with time. During term time, users are 
concentrated in the seated area of the room while during vacation, they are more in the circulation areas. Although the library operates a 24-hour opening policy during term time, the most popular period is found to be $3 \mathrm{pm}-10 \mathrm{pm}$. Although there is a mini-peak in occupancy density just after mid-night, for most of the period between 1 am and 9 am, this room is vacant or occupied by only 1 or 2 users. This room could be closed and users in this and other sparsely occupied study spaces could be directed to a common appropriate space resulting in significant reduction of (lighting) energy use. Furthermore, the library could shift its opening hours towards evening in the summer vacation period, as people still need the library after the current library closure time. Detailed analysis of energy waste patterns throughout the test period has been conducted using the method of data association rule mining. It is shown that the time period of 1 - 9 am was responsible for far more lighting energy waste (71\%) than any other 8-hour period during the whole experiment time, although there was significant variation between weekdays and weekends. If this room or the library was closed during this period, the total energy waste could be reduced by $26.1 \%$. For future work, it is suggested that more room types with diverse functions and other seasons like spring term and Christmas Vacation are included. The work could be extended to other types of academic buildings and reveal other aspects of occupation including occupancy duration and 
returning patterns for a more comprehensive understanding of building user behaviour and energy efficiency.

\section{Acknowledgements}

We sincerely thank Accuware for generously providing a 6-month free education account for web-based indoor positioning data generation, storage and retrieval.

We also express great appreciation to the facility manager of the University library, Mr Robin Hunter, for valuable facilitation of the study.

\section{References}

[1] Masoso O T, Grobler L J. The dark side of occupants' behaviour on building energy use [J]. Energy and buildings, 2010, 42(2): 173-177.

[2] D'Oca S, Hong T. Occupancy schedules learning process through a data mining framework [J]. Energy and Buildings, 2015, 88: 395-408.

[3] Nguyen T A, Aiello M. Energy intelligent buildings based on user activity: A survey [J]. Energy and buildings, 2013, 56: 244-257.

[4] Azar E, Menassa C C. Agent-based modeling of occupants and their impact on energy use in commercial buildings [J]. Journal of Computing in Civil Engineering, 2011, 26(4): 506-518.

[5] Zeng Y, Zhang Z, Kusiak A. Predictive modeling and optimization of a multi- 
zone HVAC system with data mining and firefly algorithms[J]. Energy, 2015, 86: 393-402.

[6] Yang Z, Becerik-Gerber B. The coupled effects of personalized occupancy profile based HVAC schedules and room reassignment on building energy use [J]. Energy and Buildings, 2014, 78: 113-122.

[7] Yun G Y, Kim H, Kim J T. Effects of occupancy and lighting use patterns on lighting energy consumption [J]. Energy and Buildings, 2012, 46: 152-158.

[8] Spataru C, Gillott M, Hall M R. Domestic energy and occupancy: a novel post-occupancy evaluation study [J]. International Journal of Low-Carbon Technologies, 2010: ctq020.

[9] Coleman M, Wright $A$ J, Brown $\mathrm{N}$, et al. Domestic information, communication and entertainment (ICE) appliance monitoring: a practical perspective and implications for inter-disciplinary research[J]. 2009.

[10] Darby S, The smart way to display, Energy Saving Trust, CO183, 2009.

[11] Coleman M J, Irvine K N, Lemon M, et al. Promoting behaviour change through personalized energy feedback in offices [J]. Building Research \& Information, 2013, 41(6): 637-651.

[12] Shao L, Foster R, Coleman M, et al. Wireless Energy Behaviour monitoring (Wi-be) for office buildings, International Journal of Low-Carbon Technologies [J]. 2015.

[13] Guan Q, Li C, Guo X, et al. Compressive classification of human motion 
using pyroelectric infrared sensors[J]. Pattern Recognition Letters, 2014, 49: 231-237.

[14] Nagy, Z., Yong, F. Y., Frei, M., \& Schlueter, A. (2015). Occupant centred lighting control for comfort and energy efficient building operation. Energy and Buildings, 94, 100-108.

[15] Gunay B., Fuller A., O'Brien W, Beausoleil-Morrison I. Detecting occupants' presence in office spaces: a case study. eSim 2016 Conference, Hamilton DOI: 10.13140/RG.2.2.18486.09280.

[16] Page J, Robinson D, Morel N, et al. A generalised stochastic model for the simulation of occupant presence[J]. Energy \& Buildings, 2008, 40(2):83-98.

[17] Dodier R H, Henze G P, Tiller D K, et al. Building occupancy detection through sensor belief networks[J]. Energy \& Buildings, 2006, 38(9):1033-1043. [18] Maniccia D, Luan X. Methods for Assessing the Maintained and Initial Detection Performance of Occupancy Sensors[J]. Journal of the Illuminating Engineering Society, 2013, 23(2):108-115.

[19] Hailemariam E, Goldstein R, Attar R, et al. Real-time occupancy detection using decision trees with multiple sensor types. [C]// Spring Simulation MultiConference, Springsim '11, Boston, Ma, Usa, April 03-07, 2011. Volume 8: Proceedings of the 2011 Symposium on Simulation for Architecture and Urban Design. 2011:141-148.

[20] Dong B, Andrews B, Lam K P, et al. An information technology enabled 
sustainability test-bed (ITEST) for occupancy detection through an environmental sensing network[J]. Energy \& Buildings, 2010, 42(7):1038-1046. [21] Arora. A, Amayri. M, Badarla. V, Ploix. S, Bandyopadhyay. S, Occupancy estimation using non-intrusive sensors in energy efficient buildings, in: Building Simulation 2015, 2015 (Hyderabad, India).

[22] Pothuganti K, Chitneni A. A comparative study of wireless protocols: Bluetooth, UWB, ZigBee, and Wi-Fi [J]. Adv. Electron. Electr. Eng, 2014, 4(6): 655-662.

[23] Liu Y Y. Research on library lighting intelligent control based on infrared image processing techniques [J]. Optik-International Journal for Light and Electron Optics, 2015, 126(18): 1559-1561.

[24] Subhan F, Hasbullah H, Rozyyev A, et al. Indoor positioning in bluetooth networks using fingerprinting and lateration approach[C]//201/nternational Conference on Information Science and Applications. IEEE, 2011: 1-9.

[25] Carbon Trust. Energy efficiency and carbon saving advice for the further and higher education sector.2012.

https://www.carbontrust.com/resources/guides/sector-based-advice/furtherand-higher-education. Accessed on $29^{\text {th }}$ June, 2016. [26]Navizon.https://www.accuware.com/support/wi-fi-location-monitor introduction/. 2016. Accessed on 29th May 2016. [27] Wang Y, thesis title, Master of Science Dissertation, University of Reading, 
2016.

[28] The handbook of data mining [M]. Mahwah, NJ/London: Lawrence Erlbaum Associates, Publishers, 2003.

[29] Zheng Z, Kohavi R, Mason L. Real world performance of association rule algorithms[C]//Proceedings of the seventh ACM SIGKDD international conference on Knowledge discovery and data mining. ACM, 2001: 401-406.

[30] Borgelt C, Kruse R. Induction of association rules: Apriori implementation[C]//Compstat. Physica-Verlag HD, 2002: 395-400. 